\title{
Dissemination of Agricultural Information to Farmers using ICT
}

\author{
Oyindeinbofa Nicholas-Ere \\ Kobe Institute of Computing, Graduate School \\ 2 Chome-2-7 Kanocho, Chuo, Kobe, Hyōgo Prefecture 650-0001 \\ Japan.
}

\begin{abstract}
Over the years, rural farmers in Nigeria depend on indigenous or local knowledge for improved agricultural practices. This knowledge (indigenous or local knowledge) refers to the skills and experience passed from generations to generations. This knowledge/information needs ranges from planting treated seeds, animal and plant disease prevention, fertilizer application, farm machineries, proper storage of farm products, marketing techniques, co-operative and agrocultural activities etc.

This study attempts to investigate the problems rural farmers encounter accessing agricultural information, it attempts to determine and evaluate the types of information and sources of information available to farmers. For data collection, a selfprepared questionnaire was used, and the data analyzed. The findings of the study is used to design and develop an improved ICT solution/platform that would provide farmers with agriculture related information, improve crop production and quality, make market decisions, get access to modern agriculture machines and limit Middlemen involvement in agricultural trade practices.
\end{abstract}

\section{Keywords}

Information, knowledge, ICT, Rural Farmers, dissemination, Nigeria

\section{INTRODUCTION}

Rural farmers refer to farmers living in the rural areas, most of them have low level of education, their major occupation is subsistence farming and they are generally characterized by poverty, poor health condition and ignorance. Rural farmers account for the greater part of the population in the rural areas of any developing country such as Nigeria. According to Ibii, rural farmers have very limited social contact with people outside their environment, hence acquiring information to boost their social economic status is difficult for them. Socioeconomic empowerment are activities that enable an individual to perform certain tasks that can lead to his/her development, when rural people are empowered they are strong willed and are better informed to take decisions. Information is a powerful tool for empowerment, it takes away ignorance and enables an individual to be enlightened and bold.

When rural farmers lack access to knowledge and information necessary to help them achieve maximum agricultural yield they are not only left in the dark but are left with no choice than to move to urban centers in search of formal employment. Blait (1996) pointed out that the least expensive input for improved rural agricultural development is adequate access to knowledge and information in areas of new agricultural technologies, planting treated seeds, soil conservation, prevention of plants and animal diseases, fertilizer application, proper storage of farm products, marketing techniques, co-operative and other agro-cultural activities etc.

Rural farmers in Nigeria are not noted to produce enough food and when they do they find it difficult to transport it to the markets as a result of this most of their produce get damaged even before they sell, some of these rural farmers transport their produce to the market but end up selling at a loss this is probably due to some constraints that lead to lack of access to timely and up-to-date information. Such information is highly desired by these farmers and most of the time they are made available to them via extension workers, farmers association, community libraries, state and local government agricultural agencies (ADP, ENADEP etc), email or the World Wide Web (WWW) in a telecentre (Telecommons Development Group, 2000). In this modern day of information technology, telecentres provide the rural farmers with prompt and reliable information about what is happening in areas of improved seedlings, better methods of cultivation and fertilizer application, pest and weed control/eradication, new advances in livestock production and disease control etc. but telecentres are not available and if they are available they are faced with challenges ranging from electricity to funding. Where rural farmers are not faced with constraints in accessing agricultural information, traditional media such as rural radio, has been used in delivering agricultural messages to rural farmers (Munyua, 2000). Other ways of delivering these messages or information to the rural farmers include print, video, television, films, slides, pictures, drama, dance, folklore, group discussions, meetings, exhibitions and demonstrations (Munyua, 2000). The lack of access to basic agricultural knowledge and information by rural farmers in Nigeria which may be as a result of certain constraints has made these farmers to stick to their old traditional methods of farming system and animal husbandry practice, hence resulting in poor crop and livestock productivity. Information and knowledge are very vital in agricultural development of any community and where they are poorly disseminated the community's agricultural development becomes highly impeded. Therefore, this study was carried out to investigate the constraints of the rural farmers in Nigeria in accessing agricultural information and the possible methods that can be used to effectively, efficiently, timely and cheaply provide this information to them. 


\section{CURRENT ICT SITUATION IN NIGERIA}

The literature reviews several information dissemination models used in Nigeria and other countries.

A review of various literature of information service models with the hope of achieving the following goals.

$>$ Provide Farmers with a Platform where they can get information on agriculture

$>$ Display their product and make market decisions.

$>$ Get information on fertilizers

> Improve their knowledge on modern Agric Practices

A look at the various information service models, operational features, application examples, their advantages and disadvantages one will notice that all of them have their own draw backs, I am proposing on a website and mobile app to help tackle the issue of agriculture information dissemination.

\section{Website}

$>$ I am proposing a website where farmers can display their produce, advertise their farms

$>$ I am proposing a website with offline accessibility

\section{Mobile App}

$>$ With Facebook chat capabilities

$>$ With current market Price access for taking market survey and making market decision

$>$ With Information on Mechanized farming tools

$>$ With inclusion of contacts of farmers to discourage the influence of middlemen in market transactions.

$>$ Offline Accessibility

With the rapid development of ICT, the agriculture information dissemination models are constantly evolving. The agricultural information dissemination models in Nigeria can be classified into:

1) Web portal - A collection of relevant websites to form a one stop portal for users, e.g. National eAgriculture web portal (Nigeria)

2) SMS-based - Uses message-based platforms to collect and disseminate information e.g. M-Farm Kenya

3) Mobile Internet Based service - Information dissemination using Mobile Internet service Via Smart Phones, e.g. Verdant.

To determine what is the most appropriate model to be adopted, the information infrastructure, operation costs, farmers knowledge on usage, farmers information consumption behavior and most importantly local context should be taken into consideration. This section analyses the features of each model and demonstrates its applications with case studies.

\section{Web Portal}

It's a platform hosting a collection of relevant websites. It is an important and fast information dissemination channel. Nigeria is the $8^{\text {th }}$ highest user of the internet (National Bureau of Statistics(NBS) 2017) hence the government of Nigeria expects an increase in the number of agricultural websites that will be created. The establishment of web portals promotes the sharing of utilization of information resources, reduces investment and maintenance cost, and increase the service coverage and site visits (Yun Zhang, Lei Wang and Yanqing Duan 2016).

\subsection{Case study: National e-Agriculture web portal} (Nigeria)

The ministry of agriculture and rural development developed a web portal in 2016 to enhance the agricultural activities in the country and it would also help those interested in agribusiness information about Nigeria's agricultural activities. The e-agriculture web portal came up as a result of the collaboration between the Federal Ministry of Agriculture and National Information Technology Development Agency (NITDA). It's a platform where people that wants to go into agribusiness can log into and find potentials that exist in agriculture.

\section{Operational features}

1) High quality service standards. To ensure the quality and security of information services, the federal ministry of agriculture partnered with the national information technology development agency in the development of this web portal.

2) Comprehensive management and maintenance. To guarantee the sustenance of the web portal, the ministry of agriculture established a 13-Member steering committee.

3) Provision of different contents to meet farmer's needs. E-books, reports, research papers and projects and documentation on agriculture and governments food security programs can be found and downloaded for free on the web portal.

\section{Service outcomes}

The impact of the site has increased significantly over the past years. The platform has lots of features to support agribusiness with features like Resource centres for agriculture, News and opportunities, National consumption statistics, Map showing National agricultural statistics, extension education home, Rich menu on primary production and submenus, the website has significantly strengthened information dissemination effectiveness and efficiency.

\section{SMS-based}

SMS message service model operated jointly by agricultural organizations and telecom service providers (SP). The agricultural information provider edits, audits and sends the text messages through a specific telecommunication channel (Yun Zhang, Lei Wang and Yanqing Duan 2016). Mobile phones have become an important communication tool for farmers in managing agricultural production and daily life and communication with the outside world. With the increasing number of farmers who own a mobile phone the information dissemination through SMS has become a key service model (Christine Zhenwei Qiang, Andrew Dymond and Steve Esselaar 2012). 


\subsection{Case study: M-Farm Serving farmers in Kenya}

M-Farm was developed by Jamila Abass and friends to help farmers obtain a more accurate market price information regarding their produce. Previously a farmer only knows the market price offered by middlemen trying to buy their produce. Jamila Abass and friends combined their computer science and entrepreneur skills to produce an SMS and webbased solution to provide current retail price information directly to farmers.

\section{Operational features}

1) Simple, effective and efficient.

2) It relies on three unique functionalities. (1) Price enquiry module - the farmer sends an SMS to the code 3535 noting the product and location they are interested in and in less than 10 seconds the service sends them the price, which lets them decide where to sell and the other two allows farmers to buy and sell together via SMS.

\section{Service outcomes}

It has enabled farmers to access larger markets and better prices and stay up to date with agricultural market trends also limiting middlemen involvement in market decision. It has also helped to guide farmers in agricultural production, improving agricultural productivity and efficiency.

3. Mobile internet-based service

Due to low penetration rate of computers in rural households and high usage of mobile phones in Nigeria. This model is developed taking advantage of mobile internet technologies. Nigeria has a population of over 180 million people, the number of mobile subscribers has reached 150 million and the number of internet users has climbed to 97.2 million at penetration rates of $81 \%$ and $53 \%$ respectively. Nigeria is the $8^{\text {th }}$ highest user of the internet in the world (Statistics from Internetworldstats 2017).

3.1 Case study: Verdant Nigeria

Verdant aims at providing agricultural data science, market information, managerial support and access to financial services to rural farmers for improved food productions using mobile phones.

\section{Operational features}

1) Weather - this part provides climate and weather information to the farmer. Its extrapolate weather from the web and have the capacity to accept input from an administrator.

2) Farm input - this part deals on seeds, fertilizers, insecticides etc. it not only recommends farm input to them but help them with information like price, content, availability and usage information as well as a buying and selling option.

3) Soil - provides farmers information on soil with geo-location features.

4) Here we deal with data on seeds, fertilizers, insecticides, etc. It not only recommends farm input to help with the farmer's chosen crop but provides them with information like price, content, availability and usage information as well as a buying/selling option.
5) Market - dedicated to market information about different commodities displayed to the farmer with priority on their chosen crop. A buy and sell feature is also available.

\section{Service outcomes}

It is location based and tailored to the farmers specific crop choice. Provides personalized scientific agricultural information and market intelligence to crop farmers in Nigeria through a mobile application.

\section{PROBLEM ANALYSIS}

- The greatest area of information needs by rural dwellers in

Nigeria is in agriculture.

- This information needs includes planting treated seeds, soil conservation, prevention of plants and animal disease, fertilizer application, farm machineries, proper storage of farm products, marketing techniques, cooperative activities and other agro- cultural activities.

\subsection{Problem Tree}

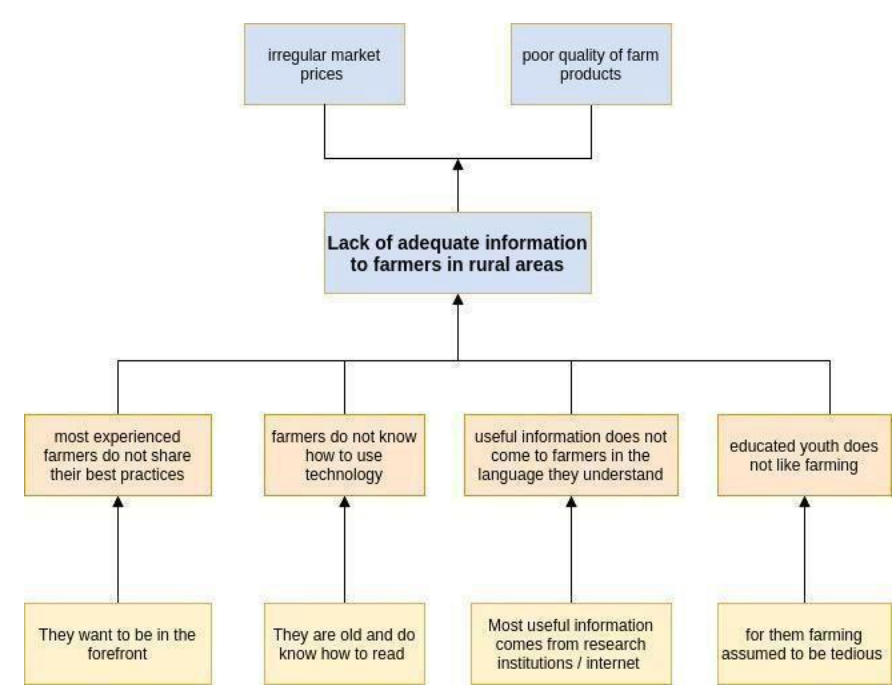

\subsection{Problem Analysis Continued}

Table 1. Types of Information Accessed by Rural Dwellers

\begin{tabular}{|c|c|c|}
\hline $\begin{array}{c}\text { Types of } \\
\text { Information } \\
\text { Needed }\end{array}$ & $\begin{array}{c}\text { Frequency of } \\
\text { Information } \\
\text { Accessed }\end{array}$ & Percentage \% \\
\hline Fertilizers & 470 & 24.4 \\
\hline Agriculture loan & 438 & 22.7 \\
\hline $\begin{array}{c}\text { Methods of } \\
\text { farming }\end{array}$ & 442 & 22.9 \\
\hline Improved seeds & 661 & 34.3 \\
\hline Pest Control & 670 & 34.8 \\
\hline $\begin{array}{c}\text { Crops In High } \\
\text { Demand }\end{array}$ & 345 & 17.9 \\
\hline $\begin{array}{c}\text { Marketing of } \\
\text { Crops }\end{array}$ & 550 & 28.5 \\
\hline Storage Methods & 584 & 30.3 \\
\hline
\end{tabular}




\section{OBJECTIVES}

Determine and Evaluate the types of information and sources of information available to farmers.

\section{HYPOTHESIS}

\subsection{If Information provision is important} to the development of agriculture in Nigeria The role information played in development of agriculture in advanced countries was checked and analyzed and the conclusion was drawn: that if information can be provided, it's up to date and can be accessed by farmers it will improve agriculture in Nigeria.

5.2 Whether or Not ICT can be used as a tool to provide information that can help develop agriculture in Nigeria.

Different ICT dissemination models was accessed and it was discovered that if well used it can improve the agriculture sector of Nigeria.

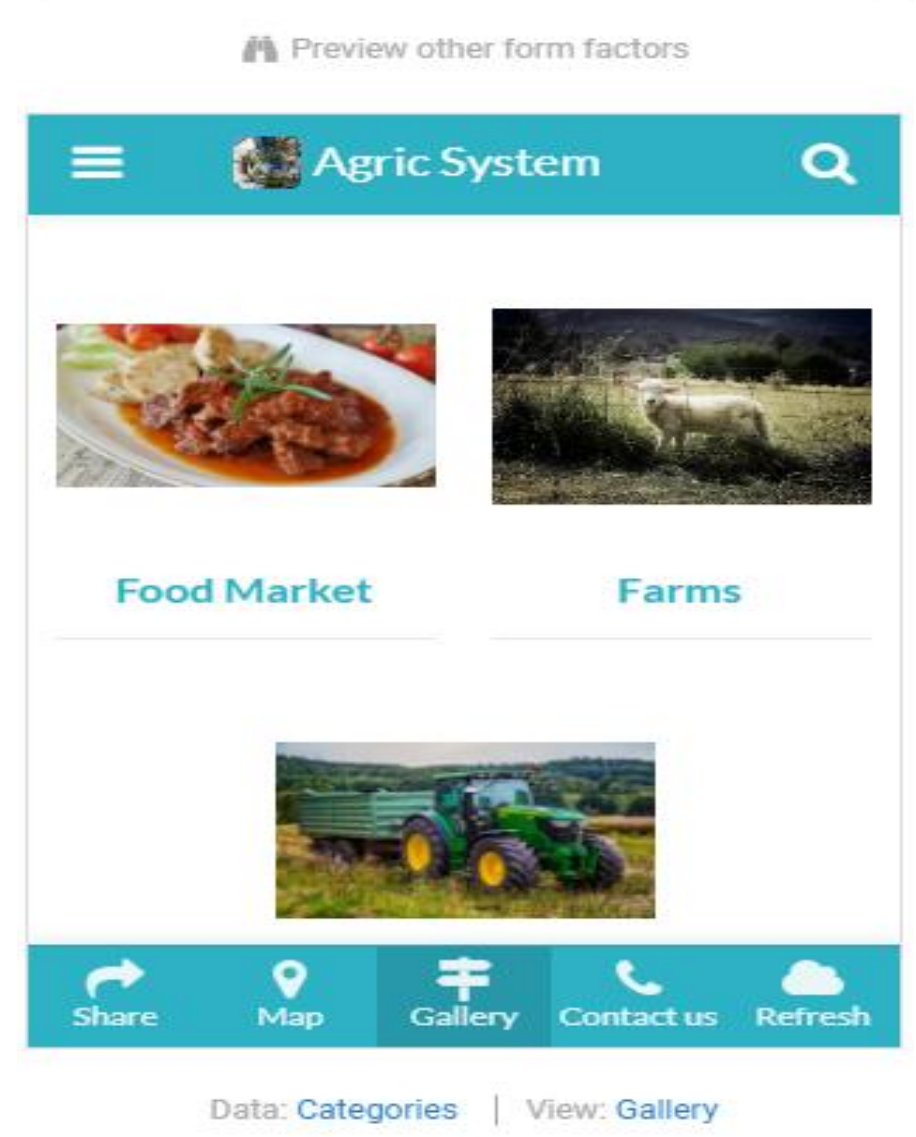

\section{POSSIBLE CONTRIBUTIONS}

It will Provide Farmers with a Platform where they

can get information on agriculture

- $\quad$ Display their product and make market decisions

- Get information on fertilizers

- Improve their knowledge on modern Agric Practices

\section{METHODOLOGY}

Quantitative method was used

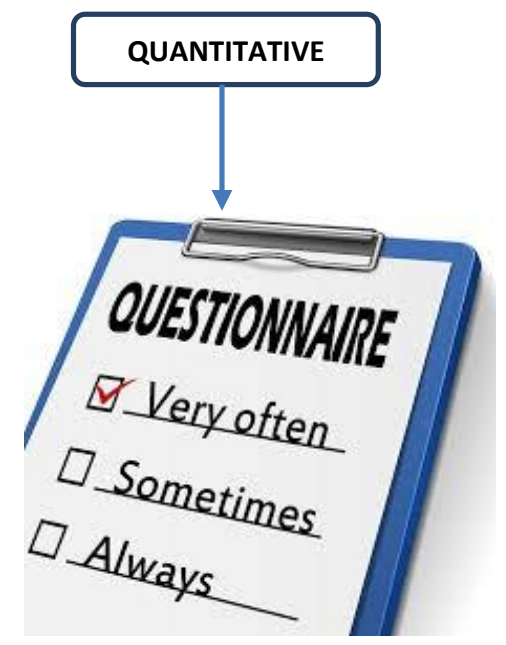

$$
\begin{aligned}
& \text { - FARMERS } \\
& \text { - TRADERS } \\
& \text { - EXTENSION WORKERS } \\
& \text { - STUDENTS OF UNIVERSITIES OF } \\
& \text { AGRICULTURE }
\end{aligned}
$$


A self-prepared questionnaire was administered through google forms to farmers, traders, extension workers and students of universities of agriculture. The question developed were based on key factors that would be used in the development of the web platform, the factors are: internet usage, internet knowledge, mobile phone access, farmers financial stability.

\section{RESULT}

Information service models - Web Portal/websites

Operational features - A collection of relevant websites to form a one stop portal for users

Application examples - National e-Agriculture web portal (Nigeria)

Advantages - Easy access, large information provision

Disadvantages - One for all information, information not comprehensive, no customization, may not be relevant to an individual user's specific information need

Information service models - SMS-based

Operational features - Dissemination of information using Mobile phone text

Application example - M-Farm Kenya

Advantages - It is commonly used, effective and efficient in sending short and timely messages.

Disadvantages - Cannot provide comprehensive and in-depth information. One for all service may also not be relevant to individual user/specific user information needs

Information service models - Mobile Internet Based service Operational features - Information dissemination using Mobile Internet service Via Smart Phones

Application examples - Verdant

Advantages - Cost effective, can incorporate GPS technology to provide location related service

Disadvantages - Require adequate infrastructure and the use of smart device. Require higher IT skills to use new technologies.

In Nigeria, national empirical data on utilization of mobile phone for agricultural extension service delivery is not available because no such survey has been conducted (Mobile Phones for Agricultural Extension 2014). However, various studies have been conducted on the utilization of mobile phone for generation and transfer of agricultural technology to farmers in different locations in Nigeria (Ovwigho 2009), also no systematic research have been carried out to understand the impact of the different information service models from enduser's perspective. The lack of empirical evaluation of all information dissemination models is a limitation of the current work. Therefore, more studies need to be conducted to evaluate different models based on end-user's feedback using rigorous and consistent criteria.

\section{CONCLUSION}

The provision of agricultural information is important to the development of agriculture and the improvement of the lives of farmers especially in the rural areas of Nigeria. It's important to note that information and knowledge are very vital in agricultural development of any community and if they are poorly disseminated that community's agricultural development becomes highly impeded. This study looks at providing information, knowledge and expert support through ICT-based information dissemination services easily and faster to farmers with the hope of improving their income and economic situation through better practices e.g. in dealing with natural disasters, pests, trading, making market decisions and with raised awareness of government support and favorable policies. This paper reviews current information service systems, with three information dissemination models identified and demonstrated with case studies.

\section{ACKNOWLEDGMENTS}

[1] Many thanks to God Almighty and the experts who have contributed towards this research also not forgetting my wonderful wife Deborah who stood by me throughout this research

\section{[2] REFERENCES}

[3] A.T. Lucky and N.E.E. Achebe (Information Communication Technology and Agricultural Information dissemination: A Case Study of Institute of Agricultural Research (IAR). Maxwell Scientific organization, 2013.

[4] Christine Zhenwei Qiang, Siou Chew Kuek, Andrew Dymond And Steve Esselaar (Mobile Applications for Agriculture and Rural Development). ICT sector Unit World Bank, 2012

[5] Edited by R. Saravanan Associate Professor (Extension Education and Rural Sociology). New Mobile phones for agricultural extension, worldwide mAgri Innovations and Promise for future. New India Publishing Agency, Edito, 2014.

[6] Hanna Mamman Daudu and Zakari Mohammed (Information dissemination, access and utilization for socio-economic empowerment of rural people in northern states of Nigeria). Annals of library and information studies, 2013.

[7] http://www.nationsencyclopedia.com/economies/Africa/ Nigeria- AGRICULTURE.html\#ixzz4wfphbwvE

[8] Information dissemination, access and utilization for socio-economic empowerment of rural people in northern states in Nigeria.

[9] Nnenna A. Obidike (Rural Farmers problems accessing agricultural information: Case Study of Nsukka Local Government Area of Enugu state, Nigeria). Library Philosophy and Practice (ejournal), 2011.

[10] Yun Zhang, Lei Wang and Yanqing Duan (Agricultural Information dissemination using ICT: Review and Analysis of information dissemination models in China). Production and hosting by Elsevier B.V., 2016. 